\title{
CONSIDERAÇÕES CLÍNICAS DAS LESÕES CERVICAIS NÃO CARIOSAS
}

\section{CLINICAL CONSIDERATIONS ABOUT THE NON-CARIOUS CERVICAL LESIONS}

\author{
Márcio Grama Hoeppner ${ }^{*}$, Simone Massarollo², Laerte Luiz Bremm ${ }^{1}$ \\ 1* Universidade Paranaense - UNIPAR, Departamento de Odontologia, Campus Umuarama, \\ PR, Brasil; (44) 3621.2844 - ramal 1245; e-mail: hoeppner@unipar.br \\ 2 Cirurgiã-dentista
}

Recebido para publicação em 22/03/2007

Aceito para publicação em 07/02/2008

\section{RESUMO}

Quanto à etiologia, as lesões não cariosas que comprometem a região cervical dos elementos dentais são de caráter multifatorial. Decorrentes de processos crônicos de dissolução ácida, sem a presença de bactérias (erosão), do desgaste mecânico repetitivo (abrasão) e da oclusão traumática (abfração), quando presentes podem resultar em problemas de ordem estética e funcional, principalmente se, além da perda de estruturas dentais, estiver associado quadro de sensibilidade dentinária. Portanto, este trabalho tem por objetivo apresentar dados referenciais a etiologia dessas lesões que possibilitem os profissionais da área odontológica ao diagnóstico diferencial clínico, a elaboração e realização de medidas preventivas à manifestação de novas lesões, além do tratamento das lesões já existentes.

Palavras-chave: diagnóstico, oclusão dentária.

\begin{abstract}
In what refers to their etiology, non-carious lesions that affect the cervical region are multifactorial. They are a result of chronical acid dissolution without bacteria (erosion), repeated mechanical damage (abrasion), or traumatic occlusion (abfraction), and they can cause functional and esthetic problems, mainly if the loss of teeth structure is associated with dentinal sensibility. This paper aims to present referential information about the etiology of this kind of lesion, and thus help dentists find a differential clinical diagnosis and prevent the appearance of new lesions while they treat those already existing.
\end{abstract}

Key words: diagnosis, dental occlusion. 


\section{Introdução}

A presença de lesões não cariosas no terço cervical dos elementos dentais pode gerar problemas de ordem estética e funcional, decorrente da sensibilidade dentinária. Classificadas na Odontologia Restauradora em três categorias: erosão, abrasão e abfração, com freqüência são tratadas apenas a partir do momento em que são visíveis as alterações estruturais decorrentes da sua evolução. Entretanto, sabedores do quão insatisfatória demonstra ser essa forma de tratamento, reconhecemos a necessidade de intervimos também de forma preventiva e, para isso, se faz necessário conhecermos a etiologia e as características clínicas do problema.

No que tange a população mundial, observamos aumento da expectativa de vida em conseqüência da melhoria da qualidade de vida. Dessa forma, podemos supor que o número de pessoas que expõem seus dentes a um maior período de tempo a fatores etiológicos relacionados à perda progressiva e não cariosa das estruturas dentais também tem aumentado (TELLES, 2000).

Järvinen, Rytömaa e Heinonen (1991), reconhecendo o aumento da prevalência das lesões cervicais, acreditam que a identificação dos fatores de risco são de grande valia para o diagnóstico, prevenção e tratamento. Tal afirmação é ratificada por Santos et al. (2005), que creditam na capacidade de identificação dos fatores etiológicos como condição essencial a implementação de um programa preventivo e/ou a definição do plano de tratamento para evitar a evolução do quadro ou aparecimento de novas lesões.

Em relação à incidência das lesões cervicais não cariosas, essas são mais visíveis na face vestibular dos dentes de pacientes adultos, sendo que a prevalência e severidade dessas lesões aumentam com a idade. Os dentes mais acometidos são os pré-molares, devido sua localização no arco que favorece a perda de estrutura dentária pela ação de ácidos, traumatismo da escovação e interferências oclusais (BRADY e WOODY, 1977; TELLES, 2000).

As lesões não cariosas observadas na região cervical dos elementos dentais são de natureza multifatorial. Adeformação dinâmica gerada pelo stress da oclusão, especialmente em condições parafuncionais, induz, alternadamente, expansão, compressão e dobramento na região cervical do dente. Essas atividades causam a quebra do esmalte dental cervical e facilitam a permeabilidade de saliva, que leva consigo partículas de esmalte, o que resulta na exposição da dentina. Por sua vez, a dentina exposta fica predisposta a erosão, causada por agentes ácidos cariogênicos ou não, e a abrasão, decorrente da ação mecânica da escovação (LEE e EAKLE, 1984; SCHNEIDER. Disponível em URL: http://www.webodonto.com/html/artigo02.htm).

Portanto, com base na literatura pertinente, este trabalho tem por objetivo apresentar a etiologia e descrever as características clínicas das lesões cervicais não cariosas, bem como, enfatizar os diferentes tipos de tratamento passiveis de realização, de acordo com o grau de comprometimento.

\section{Desenvolvimento}

\section{Erosão}

\subsection{Etiologia}

A erosão é definida como sendo resultado da dissolução química dos tecidos dentais mineralizados (esmalte e/ou dentina), decorrente da ação de soluções ácidas e/ou quelante, sem a presença de microrganismos. O diagnóstico de áreas de erosão está diretamente relacionado a um adequado exame clínico e detalhada anamnese (BURATTO et al., 2002; FUSHIDA e CURY, 1999; MOYNIHAN, LUSSI, e JAEGGI, 2002; PEREIRA et al. 1994).

No que tange a área de manifestação, embora possa acometer as faces palatina, vestibular, incisal, oclusal e/ou múltiplas, é mais comum no terço cervical vestibular dos incisivos. Clinicamente, se mostram em forma de pires ou $\mathrm{U}$, com pouca profundidade, lisas e polidas, com bordas definidas, livres de placa e com pouco brilho. De difícil diagnóstico, na face inicial, passa desapercebida pelos cirurgiões-dentistas até que a quantidade de estrutura dental se torne perceptível. Quando há o envolvimento dentinário, sua evolução é mais rápida, pois esse tecido, dado a menor quantidade de material inorgânico, se mostra menos resistente a desmineralização ácida. Como conseqüência, o paciente pode manifestar quadro de sensibilidade provocada a estímulos externos que, com o tempo, podem induzir a formação de dentina esclerótica por parte do com- 
plexo dentino-pulpar (BEVENIUS, L'ESTRANGE e ANGMAR MANSSOM, 1988; PEREIRA et al. 1994; SOBRAL et al. 2000; TOMMASI, 2002).

Segundo Eccles (1979), a dissolução química dos tecidos dentais pode ser classificada em lesões superficiais, quando a lesão envolve apenas o esmalte; localizadas, quando atinge $1 / 3$ da dentina; e extensas, quando a lesão abrange mais de $1 / 3$ da dentina.

A erosão dental é decorrente de fatores extrínsecos, intrínsecos e idiopáticos. Os extrínsecos são ácidos de origem exógena provenientes de frutas e bebidas ácidas, indústrias químicas, piscinas cloradas e fármacos. Por sua vez, a queda do $\mathrm{pH}$ na cavidade bucal decorrente de processos fisiológicos crônicos como regurgitação do suco gástrico/vômitos (refluxo gastroesofágico, vômitos relacionados ao abuso de álcool, anorexia e bulimia nervosa), xerostomia, tratamento radioterápico, alterações metabólicas (hipertireoidismo) e acidez local dos tecidos periodontais, conseqüente da oclusão traumática, são de origem intrínseca. Já os ácidos de origem desconhecida são considerados fatores idiopáticos (FUSHIDA e CURY, 1999; PEGORARO, SAKAMOTO e DOMINGUES, 2000; SOBRAL et al., 2000; TOMMASI, 2002; XONGA e VAN-HERLE, 1973).

\subsection{Tratamento}

Dependendo do fator etiológico, do grau de comprometimento da estrutura dental e da presença de sensibilidade, as opções de tratamento para as áreas de erosão podem variar da reeducação alimentar; atenção psicológica; aplicação de agentes dessensibilizantes; laserterapia; prescrição de soluções remineralizadoras (soluções fluoretadas para bochecho, aplicação tópica de flúor ou enxaguatório a base de bicarbonato). Diante de áreas com grande destruição e/ou comprometimento estético, ainda podemos indicar a confecção de restaurações com materiais adesivos (cimento de ionômero de vidro, resina composta ou mesmo a associação desses).

\section{Abrasão}

\subsection{Etiologia}

Assim como a erosão, a abrasão dental também se caracteriza pela perda de estrutura dental. Entretanto, se diferencia na etiologia, ou seja: a abrasão ocorre em conseqüência do desgaste mecânico dental decorrente da escovação traumática, uso de dentifrícios com muito abrasivo ou hábitos nocivos. Clinicamente, embora possa acometer as diferentes áreas dos elementos dentais, é comumente evidenciada no terço cervical vestibular dos que apresentam recessão gengival, em especial os caninos e pré-molares, dada a convexidade acentuada. Tem as características de ser uma superfície dura, polida, rasa, com contorno regular e em forma de V (GRIPPO, 1991; LEE e EAKLE, 1984; TOMMASI, 2002).

\subsection{Tratamento}

Quando frente a áreas de desgaste dental no terço cervical coronário, dependendo da quantidade de estrutura dental mecanicamente desgastada, da presença de sensibilidade e do envolvimento estético, podemos optar por diferentes formas de tratamento. Assim, com maior freqüência e como medida preventiva ao aparecimento da lesão, a conduta básica é a orientação quanto ao uso correto da escova dental e dentifrício pouco abrasivo. Apresença de sensibilidade, decorrente da exposição do tecido dentinário, pode ser tratada com a aplicação de agentes dessensibilizantes; laserterapia, ou mesmo com a confecção de restaurações em cimento de ionômero de vidro, resina composta ou amálgama de prata, desde que a quantidade de tecido abrasionado permita a inserção desses materiais sem, contudo, alterar o contorno do elemento dental.

\section{Abfração}

\subsection{Etiologia}

Considerando que muitas das lesões cervicais diagnosticadas não são decorrentes única e exclusivamente da dissolução ácida e da ação mecânica de agentes abrasivos, e que afetam apenas um dente em condições clínicas em que as possibilidades etiológicas descritas até então não se mostravam presentes, passouse a creditar no trauma oclusão excêntrico a perda dental na região cervical (LEE e EAKLE, 1984; SPRANGER, 1995).

Clinicamente, as abfrações apresentam-se em 
forma de cunha, geralmente profundas e com margem definida. $O$ fato de observamos maior incidência desse tipo de lesão nos dentes inferiores, pode ser justificado se consideramos que os mesmo apresentam menor diâmetro coronário na região cervical (SCHNEIDER, 2005).

Durante a mastigação, os elementos dentais são submetidos a três tipos de forças, a saber: compressão, tração e cisalhamento. Comparada ao esmalte, decorrente as suas características histológicas, a dentina se deforma sem o risco de fraturas. Durante a mastigação, as forças laterais, geradas na superfície oclusão dos dentes posteriores, podem resultar na deflexão dos dentes. Conseqüentemente, observaremos compressão na região cervical para o lado em que o dente está se flexionando e tração no lado oposto. Considerando que os substratos esmalte e dentina possuem elevada resistência à compressão e baixa à tração, o stress da deformação gera quebras das ligações químicas entre os cristais de hidroxiapatita, com isso há aumento da permeabilidade a substâncias nos espaços formados, o que dificulta o restabelecimento das ligações químicas rompidas. A longo prazo, o trauma oclusal repetitivo resulta na exposição dentinária, que por sua vez se mostra vulnerável a dissolução ácida (erosão) e ao desgaste mecânico da escovação (abrasão) (LEE e EAKLE, 1984; SPRANGER, WEBER e KUNG, 1973).

\subsection{Tratamento}

A forma mais simples e eficiente de evitarmos o aparecimento de abfrações nos dentes é por meio do ajuste oclusal. Portanto, frente a áreas de cavitação, a primeira opção é a remoção do fator etiológico, quer seja com a confecção de placas miorrelaxantes; ajuste oclusal; terapia ortodôntica, cirurgia ortognática e/ou restaurações protéticas, nos casos mais complexos. Posteriormente, dependendo da quantidade de estrutura dental perdida, presença de sensibilidade e do envolvimento estético, podemos optar pela aplicação de agentes dessensibilizantes; laserterapia; confecção de restaurações em cimento de ionômero de vidro, resina composta ou amálgama de prata; ou mesmo a associação desses.

\section{Discussão}

A partir do aumento da estimativa de vida da população dentada, podemos considerar que, frente aos fatores desencadeantes, também há aumento das chamadas lesões cervicais não cariosas.

De acordo com a literatura correlata (PEREIRA et al., 1994; SPRANGER, 1995; Telles, 2000), a perda de estrutura dental na região cervical tem etiologia multifatorial. Assim, mais importante do que a denominação, a capacidade de reconhecer o quanto cada agente etiológico contribui à perda dental já manifestada, demonstra ser fundamental a prevenção de novas lesões ou mesmo ao tratamento das já existentes (XONGA e VAN-HERLE, 1973).

Por sua vez, Pegoraro et al. (2000) ressaltam a importância do diagnóstico das lesões cervicais ainda em estágio inicial para a implementação de um programa preventivo com o propósito de evitar a evolução do quadro ou mesmo o aparecimento de novas lesões.

Dentre os fatores que podem influenciar no surgimento e evolução das lesões cervicais não cariosas, a idade assumi um papel relevante (TELLES, 2000). Diante do fato, observamos concomitante ao envelhecimento, aumento das áreas de recessão gengival, quer seja por fatores de origem fisiológica ou patológica (escovação dental, má posição dental, trauma oclusal, doença e tratamento periodontal) (SOBRAL, GARONE NETTO e LUZ, 1996). Clinicamente, a recessão resulta na exposição do tecido dentinário radicular que, somado a freqüente queda do $\mathrm{pH}$ da cavidade bucal e/ou ao desgaste mecânico, decorrente da escovação traumática, pode favorecer o aparecimento das lesões cervicais não cariosas.

Quanto ao fator sexo, os resultados são contraditórios. No trabalho de identificação das lesões cervicais não cariosas diagnosticadas em pacientes jovens e avaliação da incidência de novas lesões, durante o pe-ríodo de 3 anos, Telles (2000) concluiu que os fatores sexo, hábitos parafuniconais, mastigação unilateral, tratamento ortodôntico e tensão não foram relevantes à presença ou não das lesões. Por sua vez, Santos et al. (2005), ao analisarem o registro de 226 lesões cervicais, em 125 fichas clínicas, de 1354 prontuários, concluíram que o gênero feminino foi o mais comprometido.

Se considerarmos a oclusão como fator etiológico principal, podemos supor que a incidência de lesões cervicais não cariosas é maior nos pacientes do sexo masculino, pois desenvolvem maior força muscular 
durante a mastigação. Da mesma forma, lesões decorrentes de hábitos parafuncionais, como bruxismo e apertamento colusal, podem ser mais evidentes em pacientes com alterações emocionais.

Quanto ao tratamento, dependendo dos fatores desencadeantes, da quantidade de estrutura dental perdida, presença ou não de sensibilidade e grau de envolvimento estético, pode variar desde a orientação quanto à técnica de escovação, uso de dentifrícios sem abrasivos, controle da ansiedade, reeducação alimentar, aplicação de agentes dessensibilizantes, laserterapia, ajuste oclusal, uso de placa interposicionadora e/ou a confecção de restaurações diretas ou indiretas (BRUGNERA JUNIOR, 2005; FERREIRA, SAMPAIO e SAMPAIO, 2001; PEREIRA, 1994; POWELL, JOHNSON e GORDON, 1995; SPRANGER, 1995).

A sensibilidade dentinária associada às lesões cervicais é decorrente da presença de túbulos dentinários abertos, expostos às alterações do meio bucal, sendo a obliteração dos mesmos uma forma de tratamento. Ressaltamos que a amplitude dessa sintomatologia é que determina qual procedimento clínico será realizado, para tanto, podemos empregar hidróxido de cálcio, fluoretos, fosfato de cálcio, oxalato de potássio, vernizes, nitrato de prata, selantes, laser, cloreto de estrôncio, materiais restauradores (amálgama de prata, cimento de ionômero de vidro e/ou resina composta), entre outras opções (BRUGNERA JUNIOR, 2005; FERREIRA, SAMPAIO e SAMPAIO, 2001; PEREIRA et al., 1994; POWELL, JOHNSON e GORDON, 1995).

Em relação à confecção de restaurações, por razões estéticas, o amálgama de prata, apesar de inúmeras vantagens, está restrito a dentes inferiores e posteriores. Ainda, se considerarmos que para a restauração de lesões cervicais não cariosas freqüentemente não se faz necessário à remoção de estrutura dentária, em benefício da retenção do material, a opção por materiais estéticos e adesivos é de grande valia. Portanto, o uso de resina composta, cimento de ionômero de vidro, ou mesmo a associação desses materiais, tem solucionado o problema estético e de sensibilidade em muitos casos de lesão cervical (FERREIRA, SAMPAIO e SAMPAIO, 2001; PEREIRA et al., 1994; POWELL, JOHNSON e GORDON, 1995). Porem, tão ou mais importante quanto o tratamento da conseqüência, o sucesso clínico das restaurações, independentemente do material empregado, se dá com o controle do fator desencadeante, que muitas vezes é multifatorial.

\section{Conclusão}

Com base na literatura consultada, podemos concluir que:

1. Dada a complexidade da etiologia, erosão, abrasão e abfração são didaticamente denominadas de lesões cervicais não cariosas, cujo termo faz referência ao processo em si, entretanto, sem considerar as causas.

2. As lesões cervicais não cariosas têm etiologia multifatorial.

3. O tratamento das lesões cervicais não cariosas é diversificado e depende da quantidade de estrutura dental perdida, presença ou não de sensibilidade e grau de envolvimento estético. Conhecer a etiologia para o diagnóstico antes que resulte na perda acentuada dos tecidos dentais mineralizados é de grande valia para instituir um tratamento no sentido de modificação dos hábitos nocivos

4. O tratamento das conseqüências, através da realização de restaurações, deve ser instituído concomitante a remoção dos fatores etiológicos.

\section{REFERÊNCIAS}

1. BEVENIUS, J; L’ESTRANGE, P.; ANGMAR MANSSOM, B. Erosion guidelines for the general practioner. Aust. dent. J., v.33, n.5, p.407-11, 1988.

2. BRADY, J.M.; WOODY, R.D.. Scanning microscopy of cervical erosion. J.Amer. Dent.Ass., v.94, p.726-9, 1977.

3. BURATTO, E.M.; ANDRADE, L.; RATH, I.B.S.; TAMES, D.R. Avaliação do potencial erosivo aos tecidos duros dentais de bebidas esportivas nacionais. Rev. ABO. v.10, n.2, p.10912, 2002.

4. BRUGNERA JUNIOR, A. Laserterapia no tratamento da hipersensibilidade dentinária. Jornal da ABROPREV, p.5, janeiro/março, 2005.

5. ECCLES, J.D.. Dental erosion of non-industrial origin: a clinical survey and classification. J. Prosth. Dent. v.42, n.6, p.649-53, 1979.

6. FUSHIDA, C.E.; CURY, J.A. Estudo in situ do efeito da frequencia de ingestão de coca-cola na erosão do esmalte-dentina 
e reversão pela saliva. Rev. Odontol. USP, v.13, n.2, p.127-34, 1999.

7. FERREIRA, S.T.; SAMPAIO, J.E.C.; SAMPAIO, A. Sensibilidade dentinária - formas de tratamento. Rev.ABO Nac., v.9, n.2, p.151-56, 2001.

8. GRIPPO, J.O. Abfracion: a new classification of hard tissue lesions of teeth. J. Esthet. Dent., v.3, n.1, p.14-19, 1991.

9. JÄRVINEN, V.K.; RYTÖMAA, I.I.; HEINONEN, O.P. Risk factors in dental erosion. J Dent Res, v.70, n.6, p.942-947, 1991.

10. LEE, W.C.; EAKLE, S. Possible role of tensile stress in the etiology of cervical erosive lesions of teeth. J. Prosth. Dent. v.52, n.3, p.374-80, 1984.

11. MOYNIHAN, P.; LUSSI, A.; JAEGGI, T. Diet and dental erosion. R. Nutritional and oral health. v.18, n.9, p.780-81, 2002.

12. PEGORARO, C.M.; SAKAMOTO, F.F.O.; DOMINGUES, L.A. Perimólise: etiologia, diagnóstico e prevenção. Rev. da APCD.v.54, n.2, p.156-61, 2000.

13. PEREIRA, J.C.; FRANCISCONE, C.E.; PEGORARO, C.N.; MOMDELLI, J. Considerações sobre a etiologia e o diagnóstico das lesões dentárias cevicais. Revista da FOB, v.2, n.3, p.50-7, 1994.

14. POWELL, L.V.; JOHNSON, G.H.; GORDON, G.E. Factors associated with clinical success of cervical abrasion/erosion restorations. Oper. Dent., v.20, n.1, p.7-13, 1995.

15. SANTOS, R.L.; BARBOSA, R.P.S.; SALES, G.C.F.; COSTA, D.M.C. Análise clínica de pacientes portadores de lesões cervicais. Odontologia. Clín.-Cientif, v.4, n.1, p.35-42, 2005.

16. SCHNEIDER, T.K.. Lesões cervicais e hipersensibilidade dentinária. Disponível em URL: http://www.webodonto.com/ html/artigo02.htm. Acessado em: 01 de novembro de 2005.

17. SPRANGER, H.; WEBER, G.; KUNG, Y.S. Untersuchungen uber die Ätiologie, Pathogenese und Therapiekonsequenzen der zervikalen Zahnhartsubstanzdefekte. Der Hessische Zahnarzt Separatum Otto-Loos-Preis 1973; 12:328-341. Apud: SPRANGER H. Investigation into the gênesis of angular lesions at the cervical region of teeth. Quintessence Int., v.26, n.2, p.149-54, 1995.

18. SPRANGER, H. Investigation into the gênesis of angular lesions at the cervical region of teeth. Quintessence Int., v.26, n.2, p.149-54, 1995.

19. SOBRAL, M.A.P.; GARONE NETTO, N.; LUZ, M.A.A.C.Fatores etiológicos da hipersensibilidade dentinária cervical. RPG. v.3, n.1, p7-15, 1996.

20. SOBRAL, M.A.P.; LUZ, M.A.A.C.; GAMA-TEIXEIRA,A.; GARONE NETTO, N. Influência da dieta liquida ácida no desenvolvimento de erosão dental. Pesq. Odontol. Brás. v.14, n.4, p.406-10, 2000.
21. TELLES, D.M. Incidência de lesões cervicais não cariosas em estudantes de odontologia e sua relação com aspectos oclusais. Bauru, 2000. 83p. Tese (Doutorado em Odontologia, área de Reabilitação Oral) - Faculdade de Odontologia de Bauru da Universidade de São Paulo.

21. TOMMASI, A.F. Diagnóstico em patologia bucal. 3. ed. São Paulo: Editora Pancast, 2002. c.6, p.98.

22. XONGA, F.A.; VAN-HERLE, A. The influence of hypertyroidism on dental erosions. Oral Surg., v.36, p.34957, 1973. 